\title{
44615 - EXPOSURE TO CARDIOPULMONARY BYPASS IS ASSOCIATED WITH DECREASED GENERATION OF ACTIVATED PROTEIN C.
}

\author{
Ravi Taneja, London Health Sciences Centre, London, ON, Canada; \\ Patricia Liaw, Henderson Research Centre; \\ Gulshan Marwaha; \\ L Guo; \\ B Kiaii; \\ N Mckenzie; \\ $M$ Quantz; \\ R Novick;
}

INTRODUCTION: Cardiac surgery is associated with an inflammatory and procoagulant response. Thrombin generation increases during cardiopulmonary bypass in spite of anticoagulation with heparin. Although its exact significance is unclear, thrombin has both procoagulant and proinflammatory effects. The objective of this study was to evaluate if exposure to cardiopulmonary bypass (CPB) and thrombin elevation are associated with appropriate activation of its regulatory anticoagulant, Activated Protein $\mathrm{C}$ (APC).

METHODS: After research ethics board approval, 12 patients (Euroscore 3-5) undergoing elective coronary artery bypass surgery (CABG) with or without $\mathrm{CPB}$ were enrolled in the study. All patients were heparinised to a heparin concentration of $3 \mathrm{IU} / \mathrm{ml}$ (Hepcon HMS, Medtronic) and ACT > 480 seconds. Blood samples were collected at 7 time points: preinduction, after heparinisation, 1 hour after institution of CPB (or completion of distal anastomosis in off-CPB group), after protamine administration, and at 0, 4 and 18 hours in Intensive Care Unit. Samples were immediately transferred into tubes containing $20 \mathrm{mM}$ benzamidine and /or $0.105 \mathrm{M}$ trisodium citrate and analyzed for thrombin generation (F1:2), Protein C (PC), APC, thrombin - antithrombin (TAT), soluble thrombomodulin (sTM) and soluble endothelial protein $\mathrm{C}$ receptor (sEPCR). Results were analyzed after correction for hemodilution on CPB and statistical analysis was conducted using the t test.

RESULTS: Exposure to CPB was associated with an increased generation of F1:2 levels as compared to off-CPB patients $(4.6 \pm 2.9$ vs $0.8 \pm 0.5 \mathrm{nmol} / \mathrm{L}, \mathrm{p}<0.05)$ (mean $\pm \mathrm{sd}$ ). Regulatory APC levels increased from $1.5 \pm 0.4$ to $3.2 \pm 1.8 \mathrm{ng} / \mathrm{ml}$ in the CPB as compared to off-CPB group $(0.98 \pm 0.6$ to $1.3 \pm 0.2, \mathrm{p}<0.05)$ at the same time point and persisted until administration of protamine. However, F1:2 to APC ratios increased significantly 1 hour after exposure to $\mathrm{CPB}(4.8 \pm 2.4)$ as compared to off-CPB patients $(0.6 \pm 0.4, \mathrm{p}<0.05)$ and remained elevated at 4 hours after ICU admission $(4.6 \pm 0.4 \mathrm{vs}$ $1.2 \pm 0.7, \mathrm{p}<0.05)$ (Figure). This was associated with increased sTM levels, which became significantly elevated during CPB (454.7 \pm 143 vs $172 \pm 222.1 \mathrm{ng} / \mathrm{ml}, \mathrm{p}<0.05)$. 
DISCUSSION: Exposure to CPB group is associated with a significant elevation of thrombin generation as compared to off-CPB surgery. However, this is not associated with a proportional increase in APC production with resultant disequilibrium in thrombin and APC in the perioperative period. Decreased production of APC is also associated with transient increased shedding of thrombomodulin from the endothelium. Since APC administration has recently been found to decrease mortality in sepsis and organ dysfunction [1], this needs further evaluation and clinical correlation in cardiac surgical patients.

REFERENCES: 1. N Engl J Med. 2001, 344: 699-709.

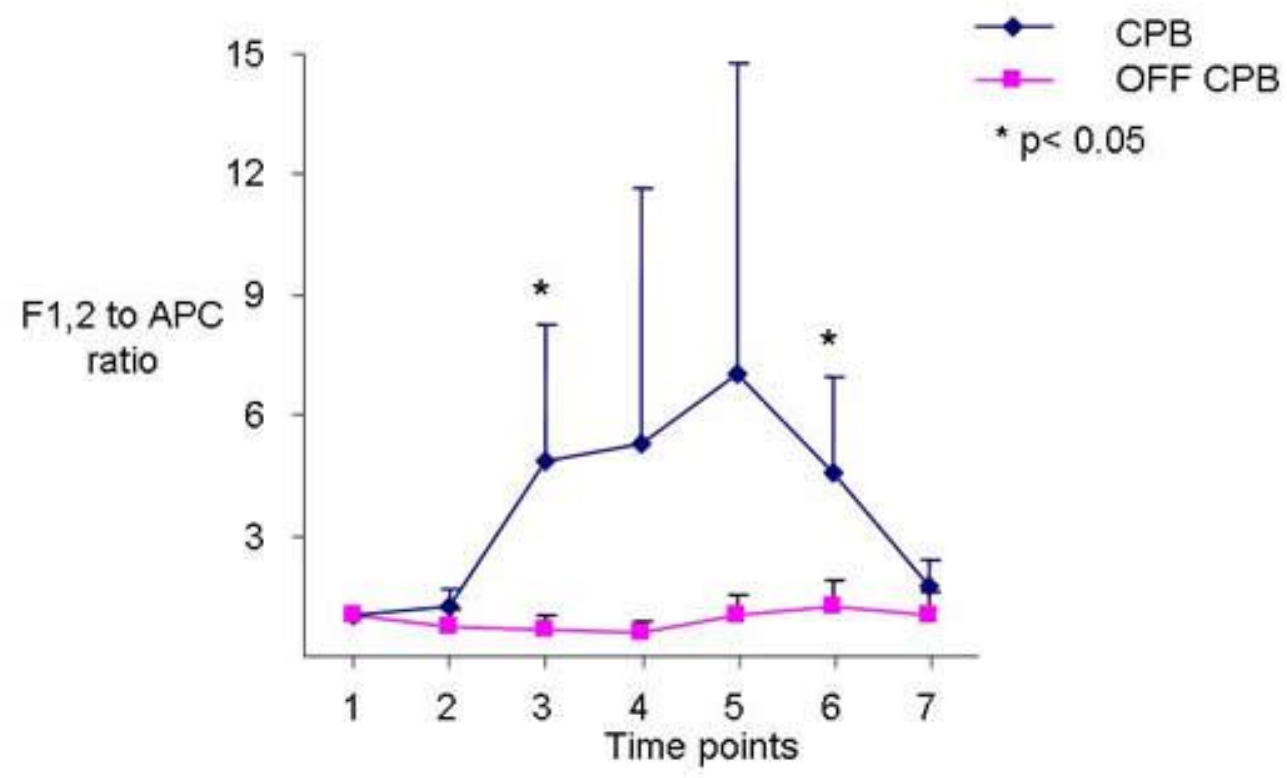

